\title{
Genome-wide association study of yield components in spring wheat collection harvested under two water regimes in Northern Kazakhstan
}

\author{
Akerke Amalova ${ }^{1,2}$, Saule Abugalieva ${ }^{1,2}$, Adylkhan Babkenov ${ }^{3}$, Sandugash Babkenova ${ }^{3}$, Yerlan Turuspekov ${ }^{\text {Corresp. } 2,4}$ \\ 1 Faculty of Biology and Biotechnology, al-Farabi Kazakh National University, Almaty, Kazakhstan \\ 2 Institute of Plant Biology and Biotechnology, Almaty, Kazakhstan \\ 3 A.I. Barayev Research and Production Centre of Grain Farming, Shortandy, Aqmola region, Kazakhstan \\ 4 Faculty of Agrobiology, Kazakh National Agrarian University, Almaty, Kazakhstan \\ Corresponding Author: Yerlan Turuspekov \\ Email address: yerlant@yahoo.com
}

Background. Bread wheat is the most important cereal in Kazakhstan, where it is grown on over 12 million hectares. One of the major constraints affecting wheat grain yield is drought due to the limited water supply. Hence, the development of drought-resistant cultivars is critical for ensuring food security in this country. Therefore, identifying quantitative trait loci (QTLs) associated with drought tolerance as an essential step in modern breeding activities, which rely on a marker-assisted selection approach.

Methods. A collection of 179 spring wheat accessions was tested under irrigated and rainfed conditions in Northern Kazakhstan over three years (2018, 2019, and 2020), during which data was collected on nine traits: heading date (HD), seed maturity date (SMD), plant height (PH), peduncle length (PL), number of productive spikes (NPS), spike length (SL), number of kernels per spike (NKS), thousand kernel weight (TKW), and kernels yield per $\mathrm{m}^{2}$ (YM2). The collection was genotyped using a 20,000 (20K) Illumina iSelect SNP array, and 8662 polymorphic SNP markers were selected for a genome-wide association study (GWAS) to identify QTLs for targeted agronomic traits.

Results. Out of the total of 237 discovered QTLs, 50 were identified as being stable QTLs for irrigated and rainfed conditions in the Akmola region, Northern Kazakhstan; the identified QTLs were associated with all the studied traits except PH. The results indicate that 9 QTLs for HD and 11 QTLs for SMD are presumably novel genetic factors identified in the irrigated and rainfed conditions of Northern Kazakhstan. The identified SNP markers of the QTLs for targeted traits in rainfed conditions can be applied to develop new competitive spring wheat cultivars in arid zones using a marker-assisted selection approach. 


\section{Genome-wide association study of yield components in spring wheat collection harvested} under two water regimes in Northern Kazakhstan

Akerke Amalova 1,2, Saule Abugalieva 1,2, Adylkhan Babkenov ${ }^{3}$, Sandugash Babkenova ${ }^{3}$, Yerlan Turuspekov ${ }^{1,4}$

1. Institute of Plant Biology and Biotechnology, Almaty, Kazakhstan

2. Faculty of Biology and Biotechnology, Al-Farabi Kazakh National University, Almaty, Kazakhstan

3. A.I. Barayev Research and Production Centre of Grain Farming, Shortandy, Kazakhstan

4. Faculty of Agrobiology, Kazakh National Agrarian University, Almaty, Kazakhstan

Corresponding Author:

Yerlan Turuspekov ${ }^{1}$

Timiryazev street 45, Almaty 050040, Kazakhstan

Email address: yerlant@yahoo.com 


\section{Abstract}

Background. Bread wheat is the most important cereal in Kazakhstan, where it is grown on over 12 million hectares. One of the major constraints affecting wheat grain yield is drought due to the limited water supply. Hence, the development of drought-resistant cultivars is critical for ensuring food security in this country. Therefore, identifying quantitative trait loci (QTLs) associated with drought tolerance as an essential step in modern breeding activities, which rely on a marker-assisted selection approach.

Methods. A collection of 179 spring wheat accessions was tested under irrigated and rainfed conditions in Northern Kazakhstan over three years (2018, 2019, and 2020), during which data was collected on nine traits: heading date (HD), seed maturity date (SMD), plant height (PH), peduncle length (PL), number of productive spikes (NPS), spike length (SL), number of kernels per spike (NKS), thousand kernel weight (TKW), and kernels yield per $\mathrm{m}^{2}$ (YM2). The collection was genotyped using a 20,000 (20K) Illumina iSelect SNP array, and 8662 polymorphic SNP markers were selected for a genome-wide association study (GWAS) to identify QTLs for targeted agronomic traits.

Results. Out of the total of 237 discovered QTLs, 50 were identified as being stable QTLs for irrigated and rainfed conditions in the Akmola region, Northern Kazakhstan; the identified QTLs were associated with all the studied traits except PH.The results indicate that 9 QTLs for HD and 11 QTLs for SMD are presumably novel genetic factors identified in the irrigated and rainfed conditions of Northern Kazakhstan. The identified SNP markers of the QTLs for targeted traits in rainfed conditions can be applied to develop new competitive spring wheat cultivars in arid zones using a marker-assisted selection approach.

Keywords: common wheat; drought tolerance; quantitative trait loci; GWAS; marker-trait associations

\section{Introduction}

Bread wheat (Triticum aestivum L.) is the most important cereal crop in Kazakhstan, where it is grown on over 12 million hectares. Kazakhstan produces up to 20 million tons of common wheat annually, exporting up to 5-7 million tons (USDA, 2018). The country is growing of spring wheat on the territory more than $80 \%$ of the total area under wheat cultivation (http://stat.gov.kz). The average grain yield is around 1.1 tons per hectare and is constrained by abiotic stresses, including drought (Shiferaw et al., 2013). Drought is a prevalent stress affecting spring wheat production in Kazakhstan's northern territories, where the frequency of severe drought ranges from $15 \%$ in Kostanai to $22 \%$ in Akmola according to averaged data for 19712011 (Patrick, 2017). The impacts of Climate change observed over the past 20 years has significantly increased the importance of drought as a challenge for crop management (Skirycz 
\& Inzé, 2010). Still, due to the need for high grain quality, bread wheat is the major agricultural commodity in the country and the preferred choice of farmers over other crops (Abugaliyeva \& Savin, 2018). Although irrigating crops with water can mitigate the impacts of drought, it leads to a substantial increase in growth costs. Therefore, the development of drought-resistant cultivars characterized by good productivity and high grain quality under stress will be critical for ensuring food security in the future (Foley et al., 2011). Drought has a significant influence on the physiological functions wheat, such as in prompting stomatal closure, decreased photosynthesis, the development of oxidative stress, and the production of toxic metabolites (Bray, 2002). Collectively, these changes in plant physiology lead to decreased plant height, reduced total shoot length, diminished growth rates, decreased number of tillers, reduced relative water content (Nezhadahmadi et al., 2013), a decline in various grain quality parameters (Tsenov et al., 2015) and, ultimately, substantial yield losses (Zhang et al., 2018). The prerequisite for the development of new competitive drought-resistant wheat cultivars is an understanding of the genetic mechanisms associated with drought stress tolerance. Previously, various genes involved in plant drought response have been distinguished and described (Ingram \& Bartels, 1996; Agarwal et al., 2006; Wei et all., 2009; Huseynova et al., 2013; Nezhadahmadi et al., 2013; Hassan et al., 2015; Kulkarni et al., 2017). In addition, several transcription factor families associated with drought in wheat have been identified, such as ethylene response factors (ERFs), dehydration responsive element binding (DREB), and zinc finger proteins (ZFPs) (Agarwal et al., 2006; Kulkarni et al., 2017). Several known genes associated with yield components, including kernel size and weight, such as TaTGW6, TaCwi-A1, TaSus2-2B, TaSus2-2A, TaSus17A, TaGW2-6A, TaGW2-6B, TaCKX6-D1, TaSAP1-A1, TaGS-D1, and TaGASR-A1, were identified in wheat drought tolerance experiments using comparative genomics approaches (Khalid et al., 2019).

Information available on drought-responsive genes is still limited as their roles have not been thoroughly determined (Bray, 2002; Nezhadahmadi et al., 2013). One of the critical aspects in identifying important genes associated with drought tolerance is considering the strong influence of the growth environment in which yield quantitative trait loci (QTLs) are identified with significant genotype $\times$ environment interaction (GEI). For instance, the results obtained from three different genome-wide association studies (GWAS) related to the identification of QTLs for yield performance in Europe (Guo et al., 2017), India (Jaiswal et al., 2016), and Mexico (Sukumaran et al., 2015), which showed different responses, and the QTLs for yield components were found to be located in different parts of the wheat genome. The sensitivity of plants to environmental factors at crucial growth phases, which determines the tolerance to stressful factors and potential yield, can explain this outcome (Reynolds et al., 2002). Therefore, the success of regional projects may largely depend on local GWAS using adapted germplasms and lead to the discovery of new genetic factors that can provide plants with characteristics of drought tolerance and high yield potential in a given environment.

The characterization of germplasm is a precondition for breeding activities as it provides novel variations that can be used for the marker-assisted breeding of crops (Nadeem et al., 2020). 
115

116

117

118

119

120

121

122

123

124

125

126

127

128

129

130

131

132

133

134

135

136

137

138

139

140

141

142

143

144

145

146

147

148

149

150

151

152

153

154

The discovery of new genes for specific agronomic traits became feasible after recent breakthroughs in the development of single nucleotide polymorphism (SNP) arrays (Cavanagh et al., 2013, Wang et al., 2014; Boeven et al., 2016; Sun et al., 2020). The availability of highthroughput SNP arrays has led to the massive genotyping of wheat germplasm collections (Allen et al., 2011; Wang et al., 2014; Sun et al., 2020), including accessions from Kazakhstan (Turuspekov et al., 2017). Hence, new molecular tools have provided rich opportunities for discovering marker-trait associations (MTA) for agronomic traits via the GWAS of wheat in different parts of the world (Rahimi et al., 2019; Tsai et al., 2020), including Kazakhstan (Turuspekov et al., 2017; Anuarbek et al., 2020; Genievskaya et al., 2020). Some QTLs associated with various drought resistance traits in wheat have been identified using linkage mapping (Quarrie et al., 2005; Verma et al., 2004; Tura et al., 2020) and association mapping via GWAS (Sukumaran et al., 2015; Li et al., 2019; Lin et al., 2019; Mathew et al., 2019). The current work is the first attempt to identify drought resistance-associated QTLs under irrigated and rainfed conditions in Northern Kazakhstan using GWAS. As Northern Kazakhstan is the region where more than $80 \%$ of the wheat-growing area is concentrated in the country, the findings are important for breeding programs aimed at developing improved wheat germplasm.

\section{Materials and methods}

\section{Phenotyping of the collection under irrigated and rainfed conditions}

In this study, we considered a collection of 179 spring bread wheat accessions including 92 commercial and prospective cultivars of Kazakhstan and Russia, 86 breeding lines from Alexandr Barayev Scientific-Production Center for Grain Farming (SPCGF, Shortandy, Akmola region), and a check cultivar for the Akmola region, Tselinnaya yubileinaya (TY, Table S1). Field experiments were conducted on the experimental plots of SPCGF $\left(51^{\circ} 36^{\prime} 09^{\prime \prime}\right.$ N, $71^{\circ} 02^{\prime} 24^{\prime \prime} \mathrm{E}, 391 \mathrm{~m}$ above sea level) in 2018, 2019, and 2020, both under irrigated and nonirrigated (rainfed) conditions. Each accession was grown in $1 \mathrm{~m}^{2}$ complete randomized block plots composed of 7 rows with 50 seeds per row in two repetitions. Field management was consistent with local practices for wheat production. Irrigation $(45 \mathrm{~mm})$ was applied at two critical stages: tillering and booting. The raw meteorological data registered for experiments are provided in Table 1 (Raw data).

The nine agronomic traits associated with drought resistance and grain productivity and used for phenology and phenotyping included the heading date (HD, days), the seed maturity date (SMD, days), plant height $(\mathrm{PH}, \mathrm{cm})$, peduncle length $(\mathrm{PL}, \mathrm{cm})$, number of productive spikes (NPS, pcs), spike length (SL, cm), number of kernels per spike (NKS, pcs), thousand kernel weight (TKW, g), kernels yield per $\mathrm{m}^{2}\left(\mathrm{YM} 2, \mathrm{~g} / \mathrm{m}^{2}\right)$.

Genotyping of the collection. Genomic DNA was extracted from a single seedling of each individual accession using the cetyltrimethylammonium bromide (CTAB) method (Doyle \& Doyle, 1990). The DNA concentration for each sample was adjusted to $30 \mathrm{ng} / \mu \mathrm{L}$. All samples of 
155

156

157

158

159

160

161

162

163

164

165

166

167

168

169

170

171

172

173

174

175

176

177

178

179

180

181

182

183

184

185

186

187

188

189

190

191

192

193

194

the 179 wheat accessions were genotyped using a 20,000 (20K) Illumina iSelect SNP array at the TraitGenetics Company (TraitGenetics GmbH, Gatersleben, Germany). A total of 8662 polymorphic SNP markers were selected for GWAS using previously published criteria (Miyagawa et al., 2008). According to these criteria, markers with call rate $\geq 90 \%$, HardyWeinberg equilibrium fit at $\mathrm{P} \geq 0.001$, a confidence score of 0.5 , and minor allele frequency (MAF) $\geq 5 \%$ were considered to meet the requirements. Accessions with greater than $15 \%$ missing data were excluded from further analysis.

\section{Analysis of linkage disequilibrium, kinship, population structure, and statistics.}

The statistics for yield trials were assessed using GraphPad Prism Version 9.0 (GraphPad Prism, 2021). GEI was analyzed using the genotype and genotype-environment (GGE) biplot method and the Finlay and Wilkinson (FW) regression analysis in GenStat software Version 19.1 (VSN International,2020). The correlation analysis was calculated using Rstudio software (RStudio Team, 2015).

A model-based clustering method (admixture models with correlated allele frequencies) in STRUCTURE v.2.3.4 software (Pritchard, Stephens \& Donnelly, 2000) was used to study the population structure of the entire collection. Five runs were conducted for each $\mathrm{K}$ ranging from 2 to 10 with a 100,000 burn-in length and 100,000 Markov chain Monte Carlo (MCMC) iterations. The optimal number of clusters $(K)$ was chosen based on the $\Delta K$ as described by Evanno, Regnaut \& Goudet, 2005. The obtained values were then transformed into a population structure (Q) matrix.

The linkage disequilibrium (LD) in the studied collection was separately calculated for each hexaploid common wheat genome (genome A, genome B, and genome D), as well as the average LD for three genomes using Java-based TASSEL v.5.2.53 software (Bradbury et al., 2007). The $\mathrm{R}$ statistical platform was used to build a plot between the pairwise $\mathrm{R}^{2}$ and the genetic distance (LD decay plot) (RStudio Team, 2015). TASSEL was also applied to calculate a population kinship matrix (Kin) based on the scaled identity using state (IBS) method (Stevens et al., 2011).

Marker-trait association analysis. The TASSEL and mixed linear model (MLM) method with the application of $K$ and $Q$ matrices was used for the identification of QTLs for agronomic traits both under irrigated and rainfed conditions. The analysis was based on QTL phenotypic data for the nine traits obtained from field trials in 2018, 2019, and 2020 and their average values over three years. $\mathrm{P}<1 \times 10^{-3}$ was used as a significant threshold for identified MTAs. The positions and sequences of the SNP markers were obtained from the $90 \mathrm{~K}$ Array Consensus map set of the common wheat genome (Wang et al., 2014). For confirmation of the correction due to $K$ and $Q$ matrices, the distribution lines in each quantile-quantile (QQ) plot were analyzed. In the case of several significant MTAs positioned closely to each other, the SNP with the lowest Pvalue was chosen. MapChart v.2.32 (Voorrips, 2002) was used to draw a genetic map. 
Candidate gene analysis. For the search for protein-coding genes that overlapped the identified significant MTAs, the sequence for each marker was used in the BLAST tool of Ensembl Plants (Ensembl Plants, 2020) for comparison against the reference genome of $T$. aestivum.

\section{Results}

\section{Phenotypic Variation and Correlation Analysis}

The field performance of the 179 local spring wheat accessions was analyzed at the SPCGF (Northern Kazakhstan) under irrigated and rainfed conditions during three field seasons in 2018, 2019 and 2020. The two-tailed $t$-test suggested that average values in all nine studied traits were significantly different between the tested irrigated and rainfed conditions. The average $\mathrm{PH}$ values showed the largest difference $(\mathrm{P}<0.0001)$ between the two tested conditions (Table1), $73.6 \mathrm{~cm}$ in irrigated in contrast to $61.6 \mathrm{~cm}$ in rainfed conditions.

Table 1. The significant differences between irrigated and rainfed trials using average data of nine traits based on a two-tailed $t$-test.

On average, YM2 declined by $5.7 \%$ under rainfed $\left(332.3 \pm 5.68 \mathrm{~g} / \mathrm{m}^{2}\right)$ compared to the irrigated $\left(352.3 \pm 4.30 \mathrm{~g} / \mathrm{m}^{2}\right)$ conditions. In total, 51 accessions exceeded the YM2 of the local standard cultivar Tselinnaya yubileinaya (TY, $374.5 \mathrm{~g} / \mathrm{m}^{2}$ ) under rainfed conditions, including nine accessions that outperformed the standard also under irrigated conditions (Fig. 1A). The Finlay and Wilkinson (FW) regression analysis (Fig. 1B) suggested that the YM2 of four wheat accessions, particularly WS10, WS32, WS82, and WS85, was stable in all three tested years (2018-2020) out of the nine accessions highlighted in the box in Figure 1A, showing YM2 values of $400 \mathrm{~g} / \mathrm{m}^{2}$ and higher.

Figure 1. The average yield performance of the best accessions under rainfed conditions. A. The list of 51 spring wheat accessions that outperformed the local check cultivar Tselinnaya yubileinaya (TY) in terms of average yield per square meter (YM2) under rainfed conditions. Accessions in orange also outperformed TY in terms of average YM2 under irrigated conditions as well. The nine accessions selected in the box, with the highest average YM2, were analyzed using Finlay and Wilkinson (FW) regression. B. The FW test suggested a different level of stability in four out of nine selected spring wheat accessions in the box in $\mathbf{A}$.

The analysis of the average YM2 using a scattered GGE biplot indicated that $52.8 \%$ of the total variance was explained by Principal Coordinate 1 (PC1), and $47.2 \%$ by PC2 (Fig.2). PC1 effectively separated accessions that showed the highest yield performance in irrigated and rainfed conditions, while PC2 split the entire collection into groups with higher and lower YM2 for both conditions. The GGE biplot graph essentially confirmed the results in Fig.1A and identified the accessions with high average YM2 under irrigated and rainfed trials as well as lines that showed high yield under both conditions (i.e., WS93 and WKZ19). 
252

253

254

255

256

257

258

259

260

261

262

263

264

265

266

267

268

269

270

271

272

273

Figure 2. Scattered GGE biplot graph of data on averaged yield per square meter (YM2) in the collection of 179 common wheat accessions tested in irrigated and rainfed conditions (2018, 2019 and 2020). Green and blue indicate Genotype and Environment scores, respectively.

Pearson's correlation assessment in both conditions indicated that average YM2 was positively correlated with NPS and TKW (Fig. 3). Interestingly, the highest correlation value of YM2 under irrigated condition was with NPS (0.39), whereas under the rainfed condition, was with NKS (0.36). We found that earlier HD was advantageous for higher TKW under rainfed conditions, while it was not a significant factor for the yield under irrigated conditions. Under rainfed conditions, a higher $\mathrm{PH}$ value was not a contributing factor to YM2 (Fig. 3A).

Interestingly, under rainfed conditions, HD influenced both SL and NKS (Fig. 3). Expectedly, PL was highly correlated with PH (P < 0.0001), but negatively associated with NPS (Fig.3A).

Figure 3. Correlation analysis for the nine agronomic traits analyzed in the collection of 179 spring wheat accessions tested in rainfed (A) and irrigated (B) conditions. Blue indicates positive correlation, and red indicates negative correlation.

\section{Genetic map, population structure, and LD}

The DNA genotyping data for studied 179 spring wheat accessions based on the use of the 20K SNP Illumina array resulted in the identification of 8662 polymorphic SNP markers. The total map length for those 8662 SNPs was $3407.6 \mathrm{cM}$, with an average chromosome length of $162.2 \mathrm{cM}$. The density of markers in chromosomes varied from $0.1 \mathrm{SNP}$ per cM (chromosome 4D) to 1.7 SNP per cM (chromosome 6B).

Based on the results of the population analysis performed using STRUCTURE for the 179 accessions of wheat genotypes and STRUCTURE Harvester analyses, $\Delta \mathrm{K}$ was optimal at $\mathrm{K}=3$. LD decay occurred at $18.5 \mathrm{cM}$ (genome A), $13.1 \mathrm{cM}$ (genome B), and $53.8 \mathrm{cM}$ (genome D) in different genomic regions with a genome-wide $\mathrm{LD}$ decay of $5.0 \mathrm{cM}$ at $0.1 \mathrm{R}^{2}$ (Fig. $\mathrm{S} 1$ ).

\section{Marker-trait associations under irrigated and rainfed conditions}

The phenotypic data for nine agronomic traits of the 179 wheat accessions harvested under rainfed and irrigated conditions were subjected to GWAS using the 8662 polymorphic SNP markers. Out of 237 total QTLs , 50 stable QTLs were identified for irrigated and rainfed conditions in the Akmola region, Northern Kazakhstan, for HD, SMD, PL, SL, NPS, NKS, and TKW, but no QTLs were detected for PH (Tables 2, Table S2, Dataset 1). The highest number of stable QTLs was localized on the chromosomes of genome B (26), followed by genomes A (16) and D (8). In general, 25 QTLs were identified in both rainfed and irrigated conditions (Table 2, Fig. S2 ). 
277

278

279

280

281

282

283

284

285

286

287

288

289

290

291

292

293

294

295

296

297

298

299

300

301

302

303

304

305

306

307

308

309

310

311

312

313

314

315

Table. 2. The list of quantitative trait loci (QTLs) for eight studied traits identified using 179 spring wheat accessions tested under irrigated and rainfed conditions in Northern Kazakhstan (2018, 2019 and 2020).

In total, eleven stable QTLs were identified for HD (Table 2). Three of them were detected only in rainfed conditions, while eight QTLs were found from the irrigated sites. One of the QTLs that was common for both tested conditions (QHD.ta.ipbb-3B) also affected NKS (Table 2). The largest number of QTLs identified in the rainfed trials was associated with SMD (8 of 12 total QTLs). PH and PL were one of the key traits to this study, as the two tested sites highly significantly differed in these traits $(\mathrm{P}<0.0001)$. However, only two stable QTLs (QPLtaipbb$3 B 1$ and QPLtaipbb-3B2) were identified for PL, and no stable QTL was identified for PH. The small number of QTL found under both conditions were YM2 (two QTL), NKS and SL (5 QTLs), and NPS (6 QTLs). Although all seven QTLs for TKW were identified in both tested sites, only two QTLs were detected in rainfed (QTKW.ta.ipbb-7B) and irrigated (QTKW.ta.ipbb$7 A$ ) conditions (Table 2).

Among the 46 identified QTLs, 7 pleiotropic MTAs were detected under both conditions. Those pleiotropic MTAs were mapped on the 1B, 1D, 2B, 3B, 5A, 6A, and 7A chromosomes and associated with HD (wsnp_Ex_c8240_13914674 and Excalibur_c20376_615) and spikerelated traits (NPS, NKS, and TKW) (Table S3, Fig. S2).

\section{Discussion}

\section{Yield assessment in the spring wheat collection under irrigated and rainfed conditions in Northern Kazakhstan}

The analysis of the collection under the two tested conditions suggested substantial differences between irrigated and rainfed fields (Table 1), indicating that limitation of water supply significantly affected all nine analyzed traits in the study. Particularly, the largest difference between two sites was found for $\mathrm{PH}$, which is congruent with results reported earlier (Tsenov et al., 2015, Lehar et al., 2019, Pour-Aboughadareh et al., 2020). The analysis of average YM2 revealed that under rainfed conditions, more than 51 common wheat accessions exceeded the YM2 of the local standard cultivar, TY, in Northern Kazakhstan (Fig.1A). Particularly, nine accessions showed outstanding yield performance in comparison to the local check cultivar TY, and four of those lines displayed grain yield stability across all three years (Fig.1B), suggesting that they might be an excellent source for local drought -tolerance -related breeding projects. The GGE biplot scatter method indicated that the two main principal coordinates explained $52.8 \%$ (PC1) and $47.2 \%$ (PC2) of total variability, supporting the assumption of the high diversity of the tested collection (Fig. 2). The correlation analysis for traits under rainfed conditions suggested a significantly negative correlation between HD and TKW, an important yield component, hinting that early HD might be favorable for increased yield under stressed conditions (Fig. 3A).

\section{Comparative QTL identification for agronomic traits in irrigated and rainfed conditions using GWAS}


The GWAS analysis of the wheat collection grown under irrigated and rainfed conditions in the Akmola region of North Kazakhstan allowed the identification of 50 stable out of 237 total QTLs that were significant for eight of the studied traits (HD, SMD, PL, NPS, SL, NKS, TKW, and YM2) under both conditions (Table 2, Fig.S2). In total, 25 common QTLs for these traits were identified in both conditions (Fig. 4). Thirteen QTLs under rainfed conditions were revealed for HD (4), SMD (8), and TKW (1) that were not detected in trials at the irrigated conditions. Twelve QTLs were identified only under irrigated conditions for the following traits: SMD (2), NPS (6), NKS (1), TKW (1), and YM2 (2).

Figure 4. Number of QTLs identified under irrigated, rainfed, and both conditions in Northern Kazakhstan in 2018, 2019 and 2020.

The assessment of QTLs for phenological traits (HD and SMD) showed that only 3 out of 23 QTLs showed effects with longer days. The remaining 20 associations were found with QTLs with shorter flowering and seed maturation time (Table 2). Two QTLs for HD, QHD.ta.ipbb-2B and $Q H D$.ta.ipbb-3B, showed pleiotropic effects for NPS, NKS, and TKW. an SNP marker in QTL for SMD, QSMD.ta.ipbb-2A, was also significant in the QTL for TKW on chromosome 2A (Table 2). Interestingly, despite the stark differences between $\mathrm{PH}$ under irrigated and rainfed conditions, no QTL was detected in GWAS for this trait. Evidently, the collection's accessions are fixed for this trait, and the low variation within the studied conditions was not enough to identify any MTA.

A total of eight QTLs were identified in irrigated and rainfed trials for the spike-related traits SL and NKS. Interestingly, seven of those eight QTLs were revealed both irrigated and rainfed conditions, and three QTLs were detected only under rainfed trials (Table 2). QNKS.ta.ipbb-3B, one of the QTLs identified only in irrigated conditions, should be particularly highlighted, as it was the factor with the highest QTL effect for the trait. Still, this QTL effect may rather be a result of the pleiotropic effect of the QTL for HD, which was identified under both conditions (Table 2). TKW is known to be one of the major yield components in wheat (Quarrie et al., 2005). In this study, eight of nine QTLs for TKW were detected using trials under rainfed conditions (Table 2). Particularly, QTKW.ta.ipbb-1B and QTKW.ta.ipbb-2B showed equally high QTL effects for TKW.

A comparison of the mapped QTLs analyzed in this study with those from other previous studies indicated that ten QTLs had known associations. For TKW, two QTLs QTKW.ta.ipbb$2 B .1$ and $Q T K W$.ta.ipbb-6A were genetically mapped close to genomic regions to QTLs for this trait identified by Tura et al. (2020). Another two associations (QNPS.ta.ipbb-1B and QYM2.ta.ipbb-7B) were in the same genetic positions of QTLs identified with the analyses of six traits using GWAS based on the assessment of spring wheat in Kazakhstan (Turuspekov et al., 2017). QTKW.ta.ipbb-5A was identified in the same genetic position as in the GWAS of 285 elite spring wheat lines of wheat association mapping initiative population grown in temperate irrigated environments (Sukumaran et al., 2015). The only QTL identified for TKW that seems to be novel is $Q T K W$.ta.ipbb-7B, which was identified under rainfed conditions and has not 
357

358

359

360

361

362

363

364

365

366

367

368

369

370

371

372

373

374

375

376

377

378

379

380

381

382

383

384

385

386

387

388

389

390

391

392

393

394

395

396

previously been reported. With respect to the other identified MTAs of yield components, QNPS.ta.ipbb-2B, QNPS.ta.ipbb-5A, QSL.ta.ipbb-2D, and QTKW.ta.ipbb-6A were located in close proximity to QTLs for the same traits in the study of UK reference mapping population Avalon $\times$ Cadenza in the Northern, Central, and Southern regions of Kazakhstan (Amalova et al., 2021).

The assessment of the identified only in rainfed conditions suggested that 12 of 13 QTLs are associated with phenological traits HD and SMD (Fig. 4), which underlines the importance of plant growth-related traits in avoiding water deficiency stress. Particularly, QHD.ta.ipbb-6A and QHD.ta.ipbb-6D for HD and seven QTLs for SMD (from chromosomes 3B to 6A) were found to be essential for early flowering and seed maturation time under rainfed conditions (Table 2). The locations of QTLs for HD compared to known flowering genes showed that the position of the most important SNP for QHD.ta.ipbb-5A.1 completely coincides with the physical position of Vrn1 (587,4 Mb; Table S3). QHD.ta.ipbb-5A.3 for HD and QSMD.ta.ipbb-3B.3 for SMD were also previously identified by Sukumaran et al. (2015), confirming the robustness of the identified QTLs for HD in this study. Our literature survey indicated that the remaining nine HD and eleven SMD associations seem to be novel QTLs, as none of them were reported elsewhere (Table S3).

\section{Localization of significant SNPs in the identified QTLs for the studied agronomic traits in the wheat physical map}

The alignment of the most significant SNPs in the 50 identified stable MTAs with sequences in the Wheat Ensembl database (https://plants.ensembl.org/Triticum aestivum/Info/Index) suggested that SNPs in 43 and 7 MTAs were in genic and intergenic positions, respectively (Table S3). Interestingly, two SNPs in the QTLs for HD under rainfed conditions on homeological chromosomes 6A and 6B (QHD.ta.ipbb-6A and QHD.ta.ipbb-6B) were aligned with E3 ubiquitin-protein ligase (UPL) (Table S3). Similar to the above two QTL locations for HD, the homeological region on the distal part of the short arm of chromosome 6D also carries an MTA for HD (Table 2, Fig. 4A,B). However, the SNP in this MTA aligned to a different gene (Table S3), most probably because of poor representation of polymorphic markers in the genome D. The UPL, along with E1 ubiquitin-activating and E2 ubiquitin-conjugating enzymes, is known to participate in the ubiquitylation of proteins (Liu et al., 2020). Ubiquitylation is essential for the regulation of various biological processes, including growth and development, response to biotic and abiotic stress, and regulation of chromatin structure (Ramadan et al., 2015; Xu et al., 2021). Additional confirmation of the relationship between ubiquitylation and HD in this study is provided by the SNP alignment of QHD.ta.ipbb-1B and QHD.ta.ipbb-3B with the Wheat Ensembl database.

Particularly, $Q H D$.ta.ipbb- $1 B$ was aligned with a putative ubiquitin carrier protein, and $Q H D$.ta.ipbb-3B with ubiquitin core domain-containing protein (Table S3). In other sequence alignments of the identified QTLs, the SNP in the most significant QTL for SMD (QSMD.ta.ipbb-3B.3) was aligned with the unknown function protein. The position of the SNP for $Q T K W$.ta.ipbb-1B showed high confidence alignment with the position of a gene from 
397

398

399

400

401

402

403

404

405

406

407

408

409

410

411

412

413

414

415

416

417

418

419

420

421

422

423

424

425

426

427

428

429

430

431

432

433

434

435

Tetratricopeptide-like helical domain superfamily, which enables plants to cope with adverse environmental stresses and allows them to rapidly acclimate to new conditions (Sharma et al., 2017).

Hence, the identified SNP markers for discovered 50 stable QTLs of eight agronomic traits, including eleven QTLs for HD and twelve QTLs for SMD, can be recommended for further validation tests in spring wheat projects for efficient construction of new and highly competitive cultivars in arid zones.

\section{Conclusion}

The collection of spring wheat consisting of 179 local cultivars and promising lines showed a wide range of grain yield under two water regimes (irrigated and rainfed) in the Akmola region of northern Kazakhstan in 2018, 2019 and 2020. In total, 51 accessions exceeded the YM2 of the local standard cultivar Tselinnaya yubileinaya under rainfed conditions, including four accessions, WS10, WS32, WS82, and WS85, which were stable in all three tested years. The GGE biplot method was applied using two principal coordinates, and confirmed the collection's high yield variability under both tested conditions. The results of Pearson's correlation testing suggest that earlier HD is advantageous for higher TKW, which is one of the main yield components, under rainfed conditions. The SNP genotyping of the studied collection using the 20K Illumina SNP array allowed the identification of 8662 polymorphic SNP markers. The field phenotypic data of nine agronomic traits and polymorphic SNP data were used to identify MTA based on a GWAS. Of 237 total QTLs, 50 stable QTLs were identified in irrigated and rainfed conditions in the Akmola region, Northern Kazakhstan, by studying HD, SMD, PL, SL, NPS, NKS, TKW, and YM2. In general, 12 QTLs were identified only in irrigated, 13 QTLs only in rainfed, and 25 QTLs both rainfed and irrigated conditions. Of the 13 QTLs identified only under rainfed conditions, 12 were associated with flowering and seed maturation time, suggesting that early flowering time is essential for avoiding water deficiency stress. The literature survey indicated that 9 QTLs for HD and 11 QTLs for SMD are presumably novel genetic factors identified in irrigated and rainfed conditions, and, therefore, they can be further validated for their efficiency in wheat breeding projects.

\section{Additional Information and Declarations Competing Interests}

The authors declare that they have no competing interests.

\section{Author Contributions}

Akerke Amalova performed field work, analyzed the data, prepared figures and tables, prepared the draft, and approved the final draft.

Saule Abugalieva conceived and designed the experiments, analyzed the data, authored or reviewed drafts of the paper, and approved the final draft

Adylkhan Babkenov, Sandugash Babkenova conceived and designed the experiments, performed and designed the experiments in experimental station, and approved the final draft 
436

437

438

439

440

441

442

443

444

445

446

447

448

449

450

451

452

453

454

455

456

457

458

459

460

461

462

463

464

465

466

467

468

469

470

471

472

473

474

475

476

477

Yerlan Turuspekov raised funding for the research, conceived and designed the experiments, authored or reviewed drafts of the paper, and approved the final draft

\section{Data Availability}

The following information was supplied regarding data availability:

Raw data is available in the Supplementary file

\section{Funding}

This study was supported by 1) the grant AP08855387 "Nested association mapping for gene discovery and deployment for improvement of yield, quality, and disease resistance in bread wheat" for 2020-2022 by the Ministry of Education and Science of the Republic of Kazakhstan, and 2) BR10765056 "Creation of highly productive varieties and hybrids of grain crops based on the achievements of biotechnology, genetics, physiology, plant biochemistry for their sustainable production in various soil and climatic zones of Kazakhstan" within the framework of program-targeted financing by the Ministry of Agriculture of the Republic of Kazakhstan for 2021-2023.The funders had no role in study design, data collection and analysis, decision to publish, or preparation of the manuscript.

\section{References}

1. USDA. 2018. "Kazakhstan - Republic of Grain and Feed Update Kazakhstan Grain and Feed July Report" 2019: 11.

2. Shiferaw B., Smale M., Braun H. J., Duveiller E., Reynolds M., \& Muricho G. 2013. Crops that feed the world 10. Past successes and future challenges to the role played by wheat in global food security. Food Security, 5(3): 291-317. DOI: 10.1007/s12571-0130263-y

3. Patrick E. 2017. Drought characteristics and management in Central Asia and Turkey. FAO Water Reports; Food and Agriculture Organization of the United Nations Rome: Rome, Italy.

4. Skirycz A., \& Inzé D. 2010. More from less: plant growth under limited water. Current Opinion in Biotechnology, 21(2): 197-203. DOI: 10.1016/j.copbio.2010.03.002

5. Abugaliyeva A.I., Savin T.V. 2018. The wheat introgressive form evaluation by grain biochemical and technological properties. Vavilovskii Zhurnal Genetiki $i$ Selektsii=Vavilov Journal of Genetics and Breeding. 22(3): 353-362. DOI: $\underline{10.18699 / \mathrm{VJ} 18.371}$

6. Foley J. A., Ramankutty N., Brauman K.A., Cassidy E.S., Gerber J.S., Johnston M., Mueller N.D., O’Connell C., Ray D.K., West P.C., Balzer C., Bennett E., Carpenter S., Hill J., Monfreda C., Polasky S., Rocksrtrom J., Sheehan J., Siebert S., \& Zaks, D. P. 2011. Solutions for a cultivated planet. Nature, 478(7369): 337-342. DOI: 10.1038/nature10452

7. Bray E. A. 2002. Classification of genes differentially expressed during water-deficit stress in Arabidopsis thaliana: an analysis using microarray and differential expression data. Annals of botany, 89(7): 803-811. DOI: $\underline{10.1093 / \mathrm{aob} / \mathrm{mcf1} 104}$ 
478

8. Nezhadahmadi A., Prodhan Z. H., \& Faruq G. 2013. Drought tolerance in wheat. The Scientific World Journal, 2013 DOI:10.1155/2013/610721

9. Tsenov N., Atanasova D., Stoeva I., \& Tsenova E. 2015. Effects of drought on grain productivity and quality in winter bread wheat. Bulgarian Journal of Agricultural Science, 21(3):592-598.

10. Zhang J., Zhang S., Cheng M., Jiang H., Zhang X., Peng C., Lu X., Zhang M., \& Jin J. 2018. Effect of Drought on Agronomic Traits of Rice and Wheat: A MetaAnalysis. International journal of environmental research and public health, 15(5):839. DOI: $10.3390 /$ ijerph15050839

11. Ingram J. \& Bartels D. 1996. The Molecular Basis of Dehydration Tolerance in Plants. Annual Review of Plant Physiology and Plant Molecular Biology, 47: 377-403. DOI:10.1146/annurev.arplant.47.1.377

12. Agarwal P.K., Agarwal P., Reddy M.K., \& Sopory S.K. 2006. Role of DREB transcription factors in abiotic and biotic stress tolerance in plants. Plant cell reports, 25(12):1263-1274. DOI: 10.1007/s00299-006-0204-8

13. Wei B., Jing R., Wang C., Chen J., Mao X., Chang X., \& Jia J. 2009. Dreb1 genes in wheat (Triticum aestivum L.): development of functional markers and gene mapping based on SNPs. Molecular Breeding, 23(1): 13-22. DOI: $\underline{10.1007 / \mathrm{s} 11032-008-9209-\mathrm{z}}$

14. Huseynova I. M., Rustamova S. M., \& Mammadov A. C. 2013. Identification of Dreb1 genes involved in drought tolerance in wheat (Triticum L.). In Photosynthesis Research for Food, Fuel and the Future, 552-555.

15. Hassan N.M., El-Bastawisy Z.M., El-Sayed A.K., Ebeed H.T., \& Alla M.M.N. 2015. Roles of dehydrin genes in wheat tolerance to drought stress. Journal of advanced research, 6(2): 179-188. DOI: $10.1016 /$ j.jare.2013.11.004

16. Kulkarni M., Soolanayakanahally R., Ogawa S., Uga, Y., Selvaraj, M. G., \& Kagale S. 2017. Drought response in wheat: key genes and regulatory mechanisms controlling root system architecture and transpiration efficiency. Frontiers in chemistry, 5:106. DOI: $\underline{10.3389 / \text { fchem. } 2017.00106}$

17. Guo Z., Chen D., Alqudah A.M., Röder M.S., Ganal M.W., \& Schnurbusch T. 2017. Genome-wide association analyses of 54 traits identified multiple loci for the determination of floret fertility in wheat. New Phytologist, 214(1), 257-270. DOI: 10.1111/nph.14342.

18. Jaiswal V., Gahlaut V., Meher P.K., Mir R.R., Jaiswal J.P., Rao A.R., Balyan H.S., Gupta P.K. 2016. Genome Wide Single Locus Single Trait, Multi-Locus and Multi-Trait Association Mapping for Some Important Agronomic Traits in Common Wheat $(T$. aestivum L.) PloS one, 11(7), e0159343. DOI:10.1371/journal.pone.0159343

19. Reynolds M.P., Trethowan R., Crossa J., Vargas M., \& Sayre K.D. 2002. Physiological factors associated with genotype by environment interaction in wheat. Field crops research, 75(2-3): 139-160. DOI:10.1016/S0378-4290(02)00023-0

20. Cavanagh C.R., Chao S., Wang S., Huang B.E., Stephen S., Kiani S., Forrest K., Saintenac C., Brown-Guedira G.L., Akhunova A. \& See D., 2013. Genome-wide comparative diversity uncovers multiple targets of selection for improvement in hexaploid wheat landraces and cultivars. Proceedings of the national academy of sciences, 110(20): 8057-8062. DOI: 10.1073/pnas.1217133110

21. Wang S., Wong D., Forrest K., Allen A., Chao S., Huang E., Maccaferri M., Salvi S., Milner S., Cattivelli L., Mastrangelo A. M., Whan A., Stephen S., Barker G., Wieseke R., 
524

525

526

527

528

529

530

531

532

533

534

535

536

537

538

539

540

541

542

543

544

545

546

547

548

549

550

551

552

553

554

555

556

557

558

559

560

561

562

563

564

565

566

567

568

Plieske J., International Wheat Genome Sequencing Consortium, Lillemo M., Mather D., Appels R., Dolferus R., Brown-Guedira G., Korol A., Akhunova A. R., Feuillet C., Salse J., Morgante M., Pozniak C., Luo M., Dvorak J., Morell M., Dubcovsky J., Ganal M., Tuberosa R., Lawley C., Mikoulitch I., Cavanagh C., Edwards K. J., Hayden M., Akhunov E. 2014. Characterization of polyploid wheat genomic diversity using a highdensity 90.000 SNP array. Plant Biotechnology Journal 12(6): 787-796. doi: 10.1111/pbi.12183.

22. Boeven P.H., Longin C.F.H., Leiser W.L., Kollers S., Ebmeyer E. \& Würschum, T. 2016. Genetic architecture of male floral traits required for hybrid wheat breeding. Theoretical and Applied Genetics. 129: 2343-2357.

23. Sun C., Dong Z., Zhao L., Ren Y., Zhang N., \& Chen F. 2020. The Wheat 660K SNP array demonstrates great potential for marker-assisted selection in polyploid wheat. Plant biotechnology journal, 18(6):1354-1360. DOI: 10.1111/pbi.13361

24. Allen A. M., Barker G. L., Berry S.T., Coghill J.A., Gwilliam R., Kirby S., Robinson P., Brenchley R.C., D’Amore R., McKenzie N., Waite D., Hall A., Bevan M., N.Hall, Edwards K.J. 2011. Transcript-specific, single-nucleotide polymorphism discovery and linkage analysis in hexaploid bread wheat (Triticum aestivum L.). Plant biotechnology journal 9(9):1086-1099. DOI 10.1111/j.1467-7652.2011.00628.x

25. Turuspekov Y., Baibulatova A., Yermekbayev K., Tokhetova L., Chudinov V., Sereda G., Ganal M., Griffiths S. \& Abugalieva S. 2017. GWAS for plant growth stages and yield components in spring wheat (Triticum aestivum L.) harvested in three regions of Kazakhstan. BMC plant biology, 17(1):190. DOI: 10.1186/s12870-017-1131-2

26. Rahimi Y., Bihamta M.R., Taleei A., Alipour H., \& Ingvarsson P. K. 2019. Genomewide association study of agronomic traits in bread wheat reveals novel putative alleles for future breeding programs. BMC plant biology, 19(1): 1-19. DOI: 10.1186/s12870$\underline{019-2165-4}$

27. Tsai H.Y., Janss L.L., Andersen J.R., Orabi J., Jensen J.D., Jahoor A., \& Jensen J. 2020. Genomic prediction and GWAS of yield, quality and disease-related traits in spring barley and winter wheat. Scientific reports, 10(1): 1-15. DOI:10.1038/s41598-02060203-2

28. Anuarbek S., Abugalieva S., Pecchioni N., Laidò G., Maccaferri M., Tuberosa R., \& Turuspekov Y. 2020. Quantitative trait loci for agronomic traits in tetraploid wheat for enhancing grain yield in Kazakhstan environments. PloS one, 15(6): e0234863. DOI:10.1371/journal.pone.0234863.

29. Genievskaya Y., Turuspekov Y., Rsaliyev A., \& Abugalieva S. 2020. Genome-wide association mapping for resistance to leaf, stem, and yellow rusts of common wheat under field conditions of South Kazakhstan. PeerJ, 8: e9820.

30. Quarrie S. A., Steed A., Calestani C., Semikhodskii A., Lebreton C., Chinoy C., Steele N., Pljevljakusić D., Waterman E., Weyen J., Schondelmaier J., Habash D. Z., Farmer P., Saker L., Clarkson D. T., Abugalieva A., Yessimbekova M., Turuspekov Y., Abugalieva S., Tuberosa R., Sanguineti M-C., Hollington P. A., Aragués R., Royo A.\& Dodig D. (2005). A high-density genetic map of hexaploid wheat (Triticum aestivum L.) from the cross Chinese Spring $\times$ SQ1 and its use to compare QTLs for grain yield across a range of environments. Theoretical and Applied Genetics 110(5): 865-880. DOI 10.1007/s00122004-1902-7. 
31. Verma V., Foulkes M.J., Worland A.J., Sylvester-Bradley R., Caligari, PDS, \& Snape J.W. 2004. Mapping quantitative trait loci for flag leaf senescence as a yield determinant in winter wheat under optimal and drought-stressed environments. Euphytica, 135(3): 255-263. DOI: 10.1023/B:EUPH.0000013255.31618.14

32. Tura H., Edwards J., Gahlaut V., Garcia M., Sznajder B., Baumann U. Baumann, F. Shahinnia, Reynolds M., Langridge P., Balyan H.S., Gupta P.K., Schnurbusch T.\& Fleury D. 2020. QTL analysis and fine mapping of a QTL for yield-related traits in wheat grown in dry and hot environments. Theoretical and Applied Genetics, 133(1): 239-257. DOI: $10.1007 / \mathrm{s} 00122-019-03454-6$

33. Sukumaran S., Dreisigacker S., Lopes M., Chavez P., \& Reynolds M. P. 2015. Genomewide association study for grain yield and related traits in an elite spring wheat population grown in temperate irrigated environments. Theoretical and applied genetics, 128(2): 353-363. DOI: 10.1007/s00122-014-2435-3

34. Lin Y., Yi X., Tang S., Chen W., Wu F., Yang X., Jiang X., Shi H., Ma J., Chen G., Chen G., Zheng Y., Wei Y., \& Liu Y. 2019. Dissection of Phenotypic and Genetic Variation of Drought-Related Traits in Diverse Chinese Wheat Landraces. The Plant Genome, 12(3): 190025. DOI: 10.3835/plantgenome2019.03.0025

35. Li L., Mao X., Wang J., Chang X., Reynolds M., \& Jing R. 2019. Genetic dissection of drought and heat-responsive agronomic traits in wheat. Plant, cell \& environment. 42(9): 2540-2553. DOI: 10.1111 pce. 13577

36. Mathew I., Shimelis H., Shayanowako A.I.T., Laing M., Chaplot V. 2019. Genome-wide association study of drought tolerance and biomass allocation in wheat. PloS one, 14(12): e0225383. DOI:10.1371/journal.pone. 0225383

37. Doyle J.J., Doyle J.L. 1990. Isolation of plant DNA from fresh tissue. Focus 12:13-15.

38. Miyagawa T., Nishida N., Ohashi J., Kimura R., Fujimoto A., Kawashima M., Koike A., Sasaki T., Tanii H., Otowa T., Momose Y., Nakahara Y., Gotoh J., Okazaki Y., Tsuji S., Tokunaga K. 2008. Appropriate data cleaning methods for genome-wide association study. Journal of Human Genetics 53(10):886-893 DOI: 10.1007/s10038-008-0322-y.

39. Bradbury P.J, Zhang Z., Kroon D.E., Casstevens T.M., Ramdoss Y., Buckler ES. 2007. TASSEL: Software for association mapping of complex traits in diverse samples. Bioinformatics 23(19):2633-2635 DOI: 10.1093/bioinformatics/btm308.

40. RStudio Team 2015. RStudio: Integrated Development for R. RStudio, Inc., Boston, MA URL http://www.rstudio.com/ .

41. Stevens E.L., Heckenberg G., Roberson E.D.O., Baugher J.D., Downey T.J., Pevsner J. 2011. Inference of Relationships in Population Data Using Identity-by-Descent and Identity-by-State. PLOS Genetics, 7(9): e1002287. DOI: 10.1371/journal.pgen.1002287

42. Pritchard J.K., Stephens M., \& Donnelly P. 2000. Inference of population structure using multilocus genotype data. Genetics, 155(2): 945-959.

43. Evanno G., Regnaut S., \& Goudet J. 2005. Detecting the number of clusters of individuals using the software STRUCTURE: a simulation study. Molecular ecology, 14(8): 2611-2620.

44. GraphPad Prism 2021. Software, Inc. Available at https://www.graphpad.com/scientificsoftware/prism/ (Accessed 22 March 2021).

45. VSN International (2020). Genstat for Windows 21st Edition. VSN International, Hemel Hempstead, UK. Web page: Genstat.co.uk 
614

615

616

617

618

619

620

621

622

623

624

625

626

627

628

629

630

631

632

633

634

635

636

637

638

639

640

641

642

643

644

645

646

647

648
46. Voorrips R.E. 2002 MapChart: Software for the graphical presentation of linkage maps and QTLs. The Journal of Heredity, 93(1):77-78. DOI: 10.1093/jhered/93.1.77.

47. Ensembl Plants 2020 https://plants.ensembl.org/Triticum aestivum/Info/Index

48. Lehari K., Kumar M., Burman V., Aastha, Vaishali, Kumar V., Chand P., Singh R. Morphological, physiological and biochemical analysis of wheat genotypes under drought stress. 2019. Journal of Pharmacognosy and Phytochemistry 8(2S): 1026-1030.

49. Pour-Aboughadareh A., Mohammadi R., Etminan A., Shooshtari L., Maleki-Tabrizi N., Poczai P. (2020). Effects of Drought Stress on Some Agronomic and MorphoPhysiological Traits in Durum Wheat Genotypes. Sustainability, 12(14): 5610.

50. Amalova A., Abugalieva S., Chudinov V., Sereda G., Tokhetova L., Abdikhalyk A., Turuspekov Y. 2021. QTL mapping of agronomic traits in wheat using the UK Avalon $\times$ Cadenza reference mapping population grown in Kazakhstan. PeerJ 9:e10733 https://doi.org/10.7717/peerj.10733

51. Liu W., Tang X., Qi X., Fu X., Ghimire S., Ma R., Li S., Zhang N., \& Si H. 2020. The ubiquitin conjugating enzyme: an important ubiquitin transfer platform in ubiquitinproteasome system. International journal of molecular sciences 21(8), 2894. DOI: 10.3390/ijms21082894

52. Ramadan A., Nemoto K., Seki M., Shinozaki K., Takeda H., Takahashi H., Sawasaki T. .2015. Wheat germ-based protein libraries for the functional characterisation of the Arabidopsis E2 ubiquitin conjugating enzymes and the RING-type E3 ubiquitin ligase enzymes. BMC Plant Biology, 15: 1-15 DOI: 10.1186/s12870-015-0660-9

53. Sharma M., \& Pandey G.K. 2016. Expansion and function of repeat domain proteins during stress and development in plants. Frontiers in plant science, 6, 1218. DOI: 10.3389/fpls.2015.01218

54. Nadeem M. A., Gündoğdu M., Ercişli S., Karaköy T., Saracoğlu O., Habyarimana E., Lin X, Hatipoğlu R., Nawaz M.A., Sameeullah M., Ahmad F., Jung B.M., Chung G., Baloch F.S. 2020. Uncovering phenotypic diversity and DArTseq marker loci associated with antioxidant activity in common bean. Genes, 11: 36. DOI: 10.3390/genes 11010036

55. Khalid M., Afzal F., Gul A., Amir R., Subhani A., Ahmed Z., Mahmood Z., Xia X., Rasheed A., He Z. 2019 Molecular characterization of 87 functional genes in wheat diversity panel and their association with phenotypes under well-watered and waterlimited conditions. Frontiers in plant science, 10: 717. DOI: 10.3389/fpls.2019.00717

56. Xu M., Jin P., Liu T., Gao S., Zhang T., Zhang F., Han X., He L., Chen J., Yang J. 2021. Genome-wide identification and characterization of UBP gene family in wheat (Triticum aestivum L.) PeerJ 9:e11594 DOI:10.7717/peerj.11594 


\section{Figure 1}

The average yield performance of the best accessions under rainfed conditions

A. The list of 51 spring wheat accessions that outperformed the local check cultivar Tselinnaya yubileinaya (TY) in terms of average yield per square meter (YM2) under rainfed conditions. Accessions in orange also outperformed TY in terms of average YM2 under irrigated conditions as well. The nine accessions selected in the box, with the highest average YM2, were analyzed using Finlay and Wilkinson (FW) regression.

B. The FW test suggested a different level of stability in four out of nine selected spring wheat accessions in the box in $\mathbf{A}$. 


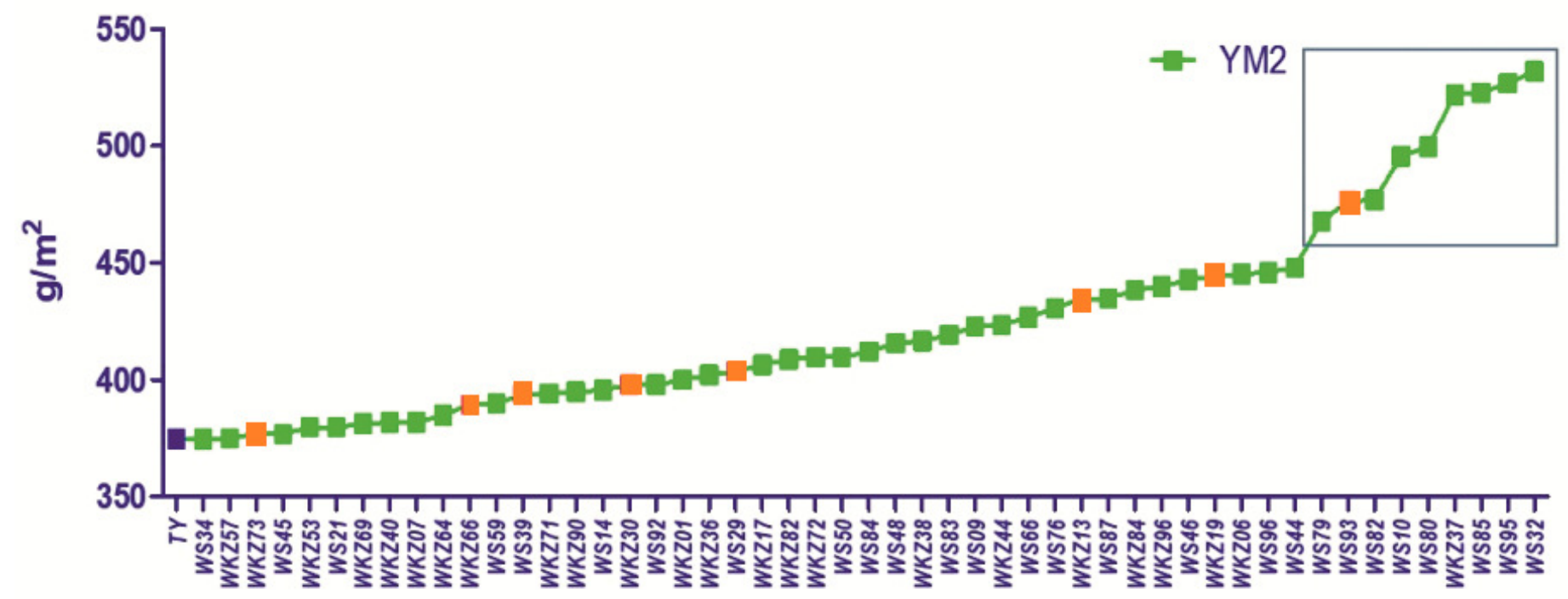

\section{A Finlay \& Wilkinson analysis}
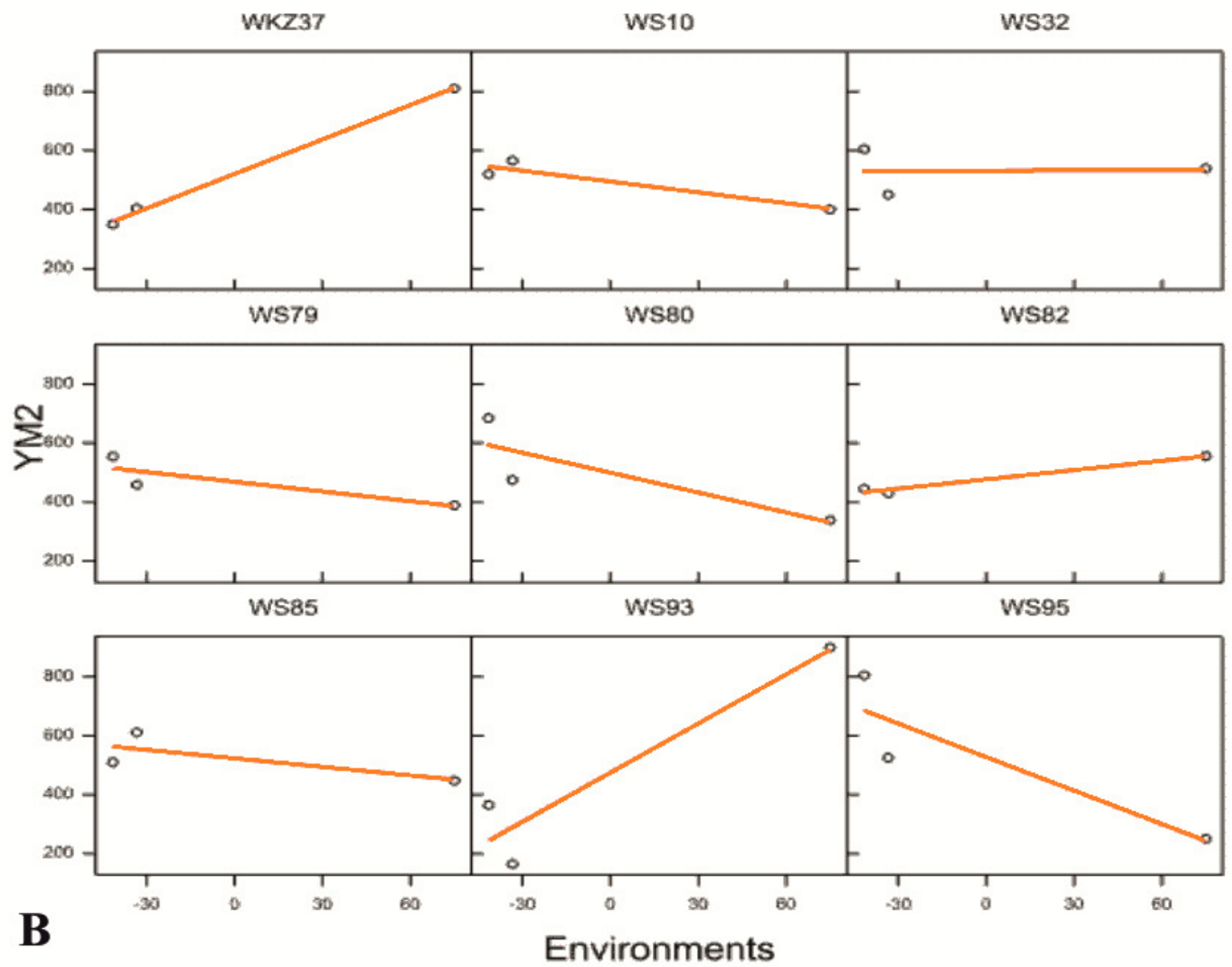
Figure 2

Scattered GGE biplot graph of data on averaged yield per square meter (YM2) in the collection of 179 common wheat accessions tested in irrigated and rainfed conditions (2018, 2019 and 2020).

Green and blue indicate Genotype and Environment scores, respectively. 


\section{Scatter plot (Total - $100.00 \%$ )}

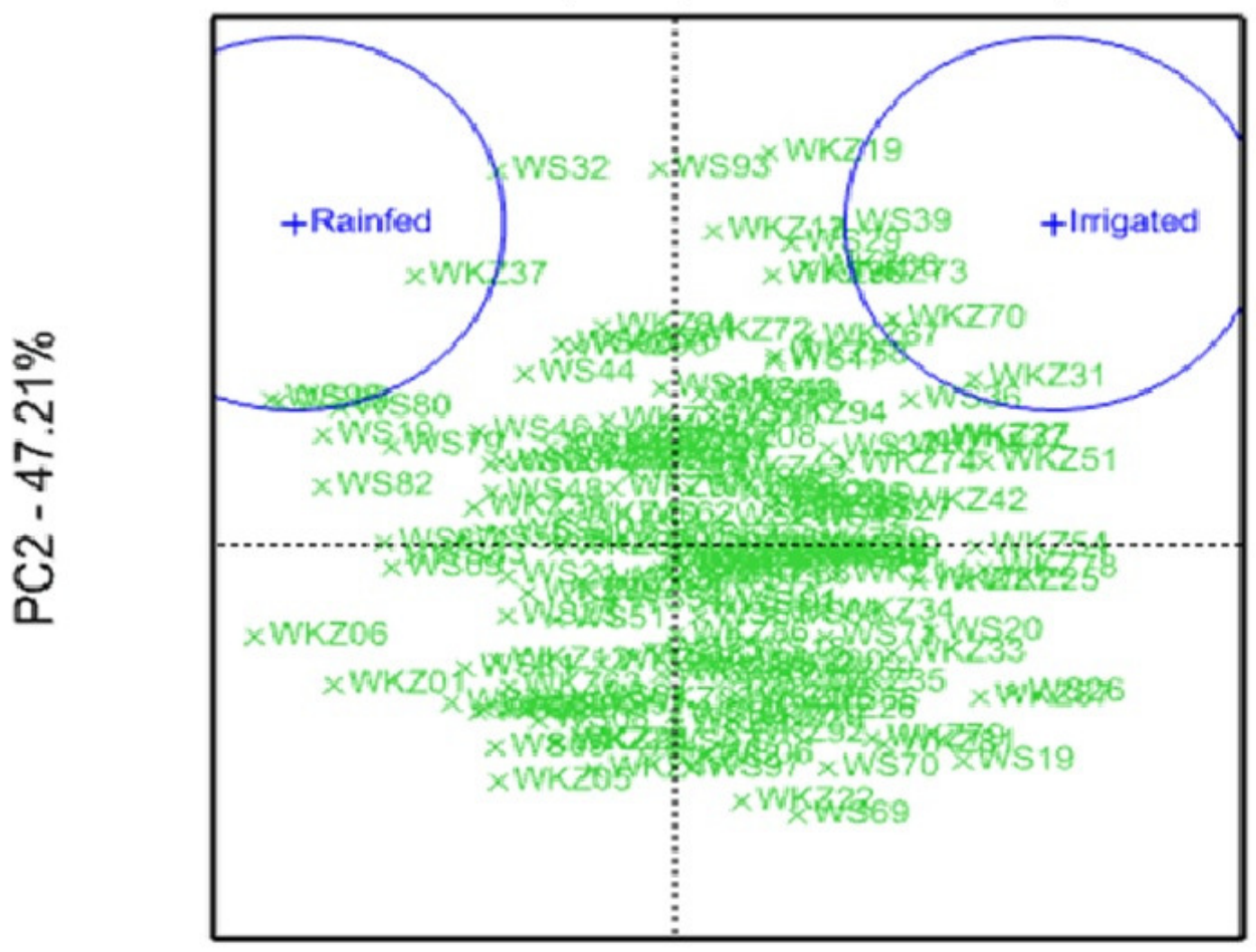

\section{PC1 - 52.79\%}

\begin{tabular}{cl|}
$\times$ & Genotype scores \\
+ & Environment scores \\
\hline & Mega-Envinonments \\
\hline
\end{tabular}


Figure 3

Correlation analysis for the nine agronomic traits analyzed in the collection of 179 spring wheat accessions tested in rainfed (A) and irrigated (B) conditions.

Blue indicates positive correlation, and red indicates negative correlation.

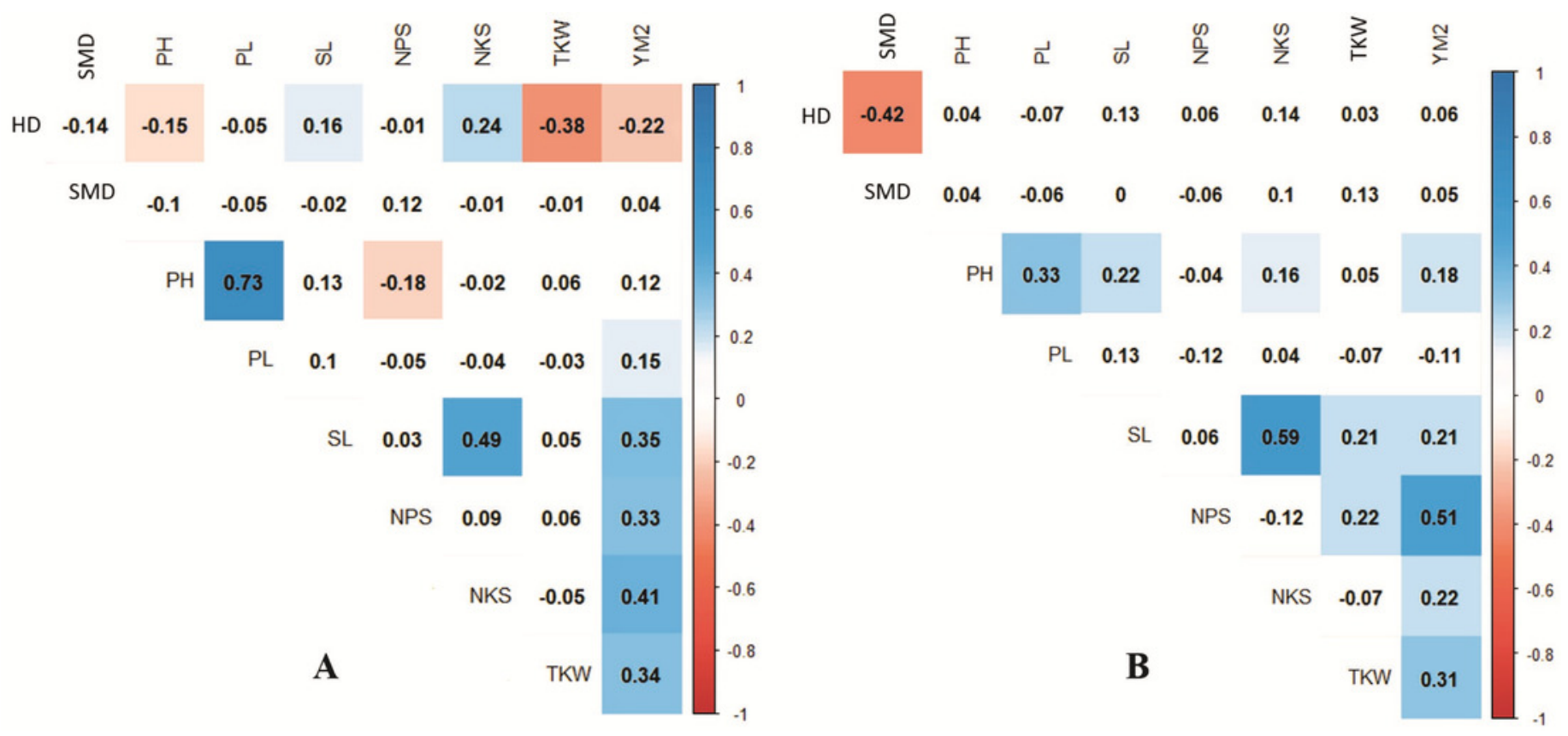


Figure 4

Number of QTLs identified under irrigated, rainfed, and both conditions in Northern Kazakhstan in 2018, 2019 and 2020

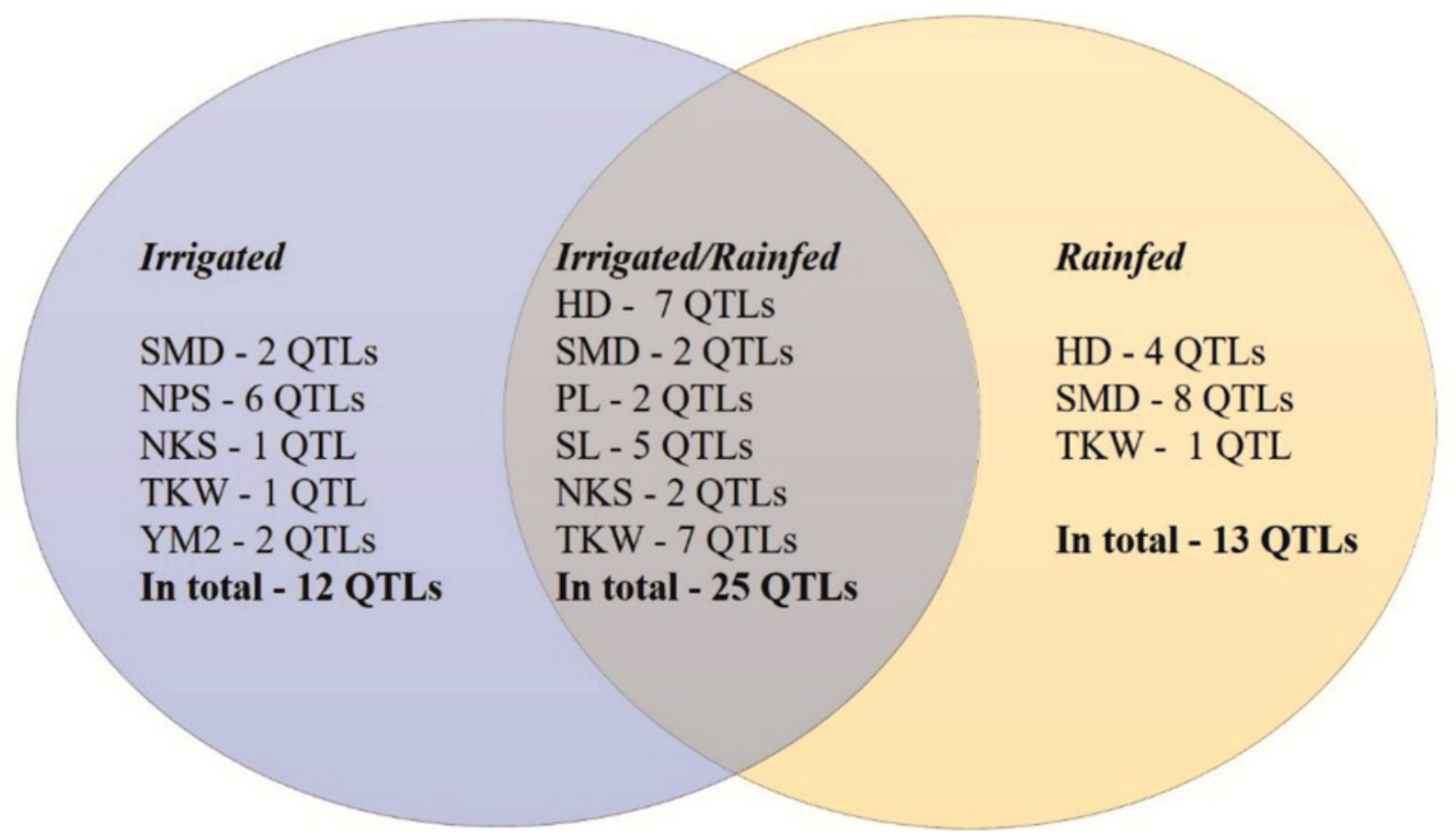




\section{Table $\mathbf{1}$ (on next page)}

The significance of differences between irrigated and rainfed trials using average data in nine traits based on a two-tailed t-test. 
1 Table 1. The significance of differences between irrigated and rainfed trials using average data in 2 nine traits based on a two-tailed t-test

\begin{tabular}{|r|l|l|l|l|}
\hline № & Traits & $\begin{array}{l}\text { Rainfed } \\
\text { (average) }\end{array}$ & $\begin{array}{l}\text { Irrigated } \\
\text { (average) }\end{array}$ & $\begin{array}{l}\text { Significance } \\
\text { (P-value) }\end{array}$ \\
\hline 1 & Heading date (HD, days) & $48.5 \pm 0.14$ & $48.1 \pm 0.15$ & 0.00260 \\
\hline 2 & Seed maturation date (SMD, days) & $49.3 \pm 0.09$ & $46.9 \pm 0.10$ & $1.97 \mathrm{E}-45$ \\
\hline 3 & Plant height (PH, cm ) & $61.6 \pm 0.39$ & $73.6 \pm 0.44$ & $4.4 \mathrm{E}-52$ \\
\hline 4 & Peduncle length (PL, cm) & $28.8 \pm 0.25$ & $32.7 \pm 0.30$ & $1.24 \mathrm{E}-19$ \\
\hline 5 & Spike length (SL, cm) & $9.05 \pm 0.05$ & $8.59 \pm 0.05$ & $8.18 \mathrm{E}-17$ \\
\hline 6 & $\begin{array}{l}\text { Number of productive spikes (NPS, } \\
\text { pcs) }\end{array}$ & $1.92 \pm 0.03$ & $2.02 \pm 0.03$ & 0.01322 \\
\hline 7 & $\begin{array}{l}\text { Number of kernels per spike (NKS, } \\
\text { pcs) }\end{array}$ & $34.9 \pm 0.28$ & $33.6 \pm 0.24$ & $1.97 \mathrm{E}-06$ \\
\hline 8 & Thousand kernel weight (TKW, g) & $35.68 \pm 0.19$ & $37.4 \pm 0.18$ & $6.3 \mathrm{E}-14$ \\
\hline 9 & $\begin{array}{l}\text { Yield per square meter (YM2, g) } \\
\text { (T32.3 }\end{array}$ & $352.3 \pm 4.30$ & 0.00592 \\
\hline
\end{tabular}

3 


\section{Table 2 (on next page)}

The list of quantitative trait loci (QTLs) for eight studied traits identified using 179 spring wheat accessions tested under irrigated and rainfed conditions in Northern Kazakhstan (2018, 2019 and 2020). 
1 Table 2. The list of QTLs for eight studied traits identified using 179 spring wheat accessions

2 tested under irrigated and rainfed conditions of Northern Kazakhstan (2018-2020)

3

\begin{tabular}{|c|c|c|c|c|c|c|c|c|}
\hline № & QTL name & SNP & Chr & Pos & P-value & Effect & Irrigated & Rainfed \\
\hline 1 & QHD.ta.ipbb-1B & Kukri_c39223_871 & $1 \mathrm{~B}$ & 75.6 & $3.77 \mathrm{E}-04$ & 4.84 & & + \\
\hline 2 & QHD.ta.ipbb-2A & $\begin{array}{l}\text { RAC875_c1706_18 } \\
88\end{array}$ & $2 \mathrm{~A}$ & 151.2 & $3.33 \mathrm{E}-04$ & -1.61 & + & + \\
\hline 3 & QHD.ta.ipbb-2B & $\begin{array}{l}\text { Excalibur_c20376_ } \\
615\end{array}$ & $2 \mathrm{~B}$ & 76.8 & $6.54 \mathrm{E}-05$ & -1.42 & + & + \\
\hline 4 & QHD.ta.ipbb-3B & $\begin{array}{l}\text { wsnp_Ex_c8240_1 } \\
3914674\end{array}$ & $3 \mathrm{~B}$ & 32.9 & $1.49 \mathrm{E}-06$ & 2.06 & + & + \\
\hline 5 & QHD.ta.ipbb-5A.1 & $\begin{array}{l}\text { BobWhite_c10385 } \\
374\end{array}$ & $5 \mathrm{~A}$ & 0.00 & $1.57 \mathrm{E}-05$ & -5.68 & + & + \\
\hline 6 & QHD.ta.ipbb-5A.2 & $\begin{array}{l}\text { wsnp_BF293620A_ } \\
\text { Ta_2_1 }\end{array}$ & $5 \mathrm{~A}$ & 58.27 & $1.94 \mathrm{E}-05$ & -2.13 & + & + \\
\hline 7 & QHD.ta.ipbb-5A.3 & BS00022071_51 & $5 \mathrm{~A}$ & 90.5 & $4.89 \mathrm{E}-05$ & -1.96 & + & + \\
\hline 8 & QHD.ta.ipbb-5B & $\begin{array}{l}\text { RAC875_rep_c109 } \\
63490\end{array}$ & $5 \mathrm{~B}$ & 125.0 & $3.45 \mathrm{E}-04$ & -1.67 & & + \\
\hline 9 & QHD.ta.ipbb-6A & $\begin{array}{l}\text { Excalibur_c28854_ } \\
1580\end{array}$ & $6 \mathrm{~A}$ & 0.88 & $1.94 \mathrm{E}-06$ & -6.89 & & + \\
\hline 10 & QHD.ta.ipbb-6B & $\begin{array}{l}\text { RAC875_c13610_1 } \\
599\end{array}$ & $6 \mathrm{~B}$ & 0.37 & $3.76 \mathrm{E}-05$ & -5.39 & + & + \\
\hline 11 & QHD.ta.ipbb-6D & $\begin{array}{l}\text { Excalibur_rep_c106 } \\
566371\end{array}$ & $6 \mathrm{D}$ & 2.56 & $8.82 \mathrm{E}-06$ & -6.34 & & + \\
\hline 12 & QSMD.ta.ipbb-2A & $\begin{array}{l}\text { RAC875_c57998_1 } \\
65\end{array}$ & $2 \mathrm{~A}$ & 101.9 & $3.23 \mathrm{E}-04$ & -3.66 & + & \\
\hline 13 & QSMD.ta.ipbb-2B.1 & Kukri_c9785_1472 & $2 \mathrm{~B}$ & 75.7 & $3.74 \mathrm{E}-04$ & -0.31 & + & + \\
\hline 14 & QSMD.ta.ipbb-2B.2 & CAP8_c5161_541 & $2 \mathrm{~B}$ & 107.5 & $2.07 \mathrm{E}-04$ & 0.47 & & + \\
\hline 15 & QSMD.ta.ipbb-2D & $\begin{array}{l}\text { Excalibur_c23239 } \\
961\end{array}$ & $2 \mathrm{D}$ & 129.0 & $1.58 \mathrm{E}-04$ & 1.75 & + & \\
\hline 16 & QSMD.ta.ipbb-3B.1 & IMX3190 & 3B & 56.6 & $5.05 \mathrm{E}-04$ & -1.40 & & + \\
\hline 17 & QSMD.ta.ipbb-3B.2 & $\begin{array}{l}\text { BobWhite_c5095_6 } \\
34\end{array}$ & 3B & 69.7 & $5.05 \mathrm{E}-04$ & -3.39 & & + \\
\hline 18 & QSMD.ta.ipbb-3B.3 & BS00078844_51 & $3 \mathrm{~B}$ & 85.0 & $5.00 \mathrm{E}-06$ & -6.32 & & + \\
\hline 19 & QSMD.ta.ipbb-3D & GENE-1805_65 & $3 \mathrm{D}$ & 71.9 & $6.63 \mathrm{E}-04$ & -3.39 & & + \\
\hline 20 & QSMD.ta.ipbb-4A & $\begin{array}{l}\text { RAC875_c40654_2 } \\
06\end{array}$ & $4 \mathrm{~A}$ & 120.1 & $1.76 \mathrm{E}-04$ & -1.28 & & + \\
\hline 21 & QSMD.ta.ipbb-5D & Jagger_c8037_96 & $5 \mathrm{D}$ & 167.0 & $6.62 \mathrm{E}-06$ & -5.35 & & + \\
\hline 22 & QSMD.ta.ipbb-6A & BS00009985_51 & $6 \mathrm{~A}$ & 60.9 & $8.25 \mathrm{E}-05$ & -5.22 & & + \\
\hline 23 & QSMD.ta.ipbb-6B & $\begin{array}{l}\text { Excalibur_c15744_ } \\
322\end{array}$ & $6 \mathrm{~B}$ & 0.37 & $8.66 \mathrm{E}-04$ & -3.36 & + & + \\
\hline 24 & QPL.ta.ipbb-3B.1 & $\begin{array}{l}\text { wsnp_Ra_c12935_ } \\
20587578\end{array}$ & 3B & 52.8 & $2.75 \mathrm{E}-04$ & -0.26 & + & + \\
\hline 25 & QPL.ta.ipbb-3B.2 & BS00030534_51 & $3 \mathrm{~B}$ & 67.4 & $3.34 \mathrm{E}-04$ & 4.76 & + & + \\
\hline 26 & QSL.ta.ipbb-1A & $\begin{array}{l}\text { wsnp_Ku_c1818_3 } \\
557408\end{array}$ & $1 \mathrm{~A}$ & 16.7 & 7.81E-04 & -0.78 & + & + \\
\hline 27 & QSL.ta.ipbb-1B & $\begin{array}{l}\text { wsnp_Ex_c26419_ }_{35667216} \\
\end{array}$ & $1 \mathrm{~B}$ & 65.4 & $5.99 \mathrm{E}-04$ & -0.95 & + & + \\
\hline 28 & QSL.ta.ipbb-2B & BS00093993_51 & $2 \mathrm{~B}$ & 108.3 & $5.64 \mathrm{E}-06$ & -1.09 & + & + \\
\hline 29 & QSL.ta.ipbb-2D & TA001453-0801 & $2 \mathrm{D}$ & 96.1 & $3.11 \mathrm{E}-04$ & -0.62 & + & + \\
\hline
\end{tabular}




\begin{tabular}{|c|c|c|c|c|c|c|c|c|}
\hline 30 & QSL.ta.ipbb-5B & $\begin{array}{l}\text { Excalibur_c9391_1 } \\
016\end{array}$ & $5 \mathrm{~B}$ & 109.5 & $1.55 \mathrm{E}-04$ & -0.78 & + & + \\
\hline 31 & QNPS.ta.ipbb-1B & BS00078431_51 & 1B & 70.8 & 7.91E-05 & 0.31 & + & \\
\hline 32 & QNPS.ta.ipbb-1D & BS00063511_51 & $1 \mathrm{D}$ & 167.1 & $8.34 \mathrm{E}-05$ & 0.29 & + & \\
\hline 33 & QNPS.ta.ipbb-2B & $\begin{array}{l}\text { Excalibur_c20376_ } \\
615\end{array}$ & 2B & 76.8 & $1.12 \mathrm{E}-05$ & 0.34 & + & \\
\hline 34 & QNPS.ta.ipbb-5A & $\begin{array}{l}\text { RAC875_rep_c112 } \\
818 \_307\end{array}$ & $5 \mathrm{~A}$ & 98.9 & $3.40 \mathrm{E}-05$ & -0.29 & + & \\
\hline 35 & QNPS.ta.ipbb-6A & TA003021-1057 & $6 \mathrm{~A}$ & 56.1 & $6.16 \mathrm{E}-04$ & 0.02 & + & \\
\hline 36 & QNPS.ta.ipbb-7A & TA003458-0086 & $7 \mathrm{~A}$ & 133.9 & $3.54 \mathrm{E}-05$ & 0.17 & + & \\
\hline 37 & QNKS.ta.ipbb-2B & Ku_c77612_301 & $2 \mathrm{~B}$ & 77.6 & $8.27 \mathrm{E}-05$ & -4.14 & + & + \\
\hline 38 & QNKS.ta.ipbb-3B & $\begin{array}{l}\text { wsnp_Ex_c8240_1 } \\
3914674\end{array}$ & 3B & 32.9 & $1.05 \mathrm{E}-06$ & 5.13 & + & \\
\hline 39 & QNKS.ta.ipbb-4B & $\begin{array}{l}\text { RAC875_c5087_31 } \\
0\end{array}$ & $4 \mathrm{~B}$ & 71.3 & $3.28 \mathrm{E}-04$ & -5.10 & + & + \\
\hline 40 & QTKW.ta.ipbb-1B & BS00078431_51 & 1B & 70.8 & $2.75 \mathrm{E}-06$ & 3.49 & + & + \\
\hline 41 & QTKW.ta.ipbb-1D & BS00063511_51 & $1 \mathrm{D}$ & 167.1 & $3.64 \mathrm{E}-05$ & 2.84 & + & + \\
\hline 42 & QTKW.ta.ipbb-2A & $\begin{array}{l}\text { wsnp_Ex_rep_c101 } \\
866 \_87158671\end{array}$ & $2 \mathrm{~A}$ & 101.9 & 4.40E-04 & 2.27 & + & + \\
\hline 43 & QTKW.ta.ipbb-2B & $\begin{array}{l}\text { Excalibur_c20376_ } \\
615\end{array}$ & $2 \mathrm{~B}$ & 76.8 & $1.98 \mathrm{E}-06$ & 3.49 & + & + \\
\hline 44 & QTKW.ta.ipbb-4B & $\begin{array}{l}\text { Excalibur_c27349_ } \\
166\end{array}$ & 4B & 77.9 & $2.67 \mathrm{E}-04$ & -2.65 & + & + \\
\hline 45 & QTKW.ta.ipbb-5A & $\begin{array}{l}\text { RAC875_rep_c112 } \\
818 \_307\end{array}$ & $5 \mathrm{~A}$ & 98.9 & 2.23E-05 & -3.02 & + & + \\
\hline 46 & QTKW.ta.ipbb-6A & TA003021-1057 & $6 \mathrm{~A}$ & 56.1 & $1.67 \mathrm{E}-06$ & -3.34 & + & + \\
\hline 47 & QTKW.ta.ipbb-7A & TA003458-0086 & $7 \mathrm{~A}$ & 133.9 & $4.56 \mathrm{E}-05$ & 2.92 & + & \\
\hline 48 & QTKW.ta.ipbb-7B & BS00063744_51 & $7 \mathrm{~B}$ & 99.2 & $2.83 \mathrm{E}-05$ & 2.68 & & + \\
\hline 49 & QYM2.ta.ipbb-3D & BS00061125_51 & $3 \mathrm{D}$ & 149.8 & $3.10 \mathrm{E}-04$ & 25.39 & + & \\
\hline 50 & QYM2.ta.ipbb-7B & $\begin{array}{l}\text { wsnp_Ex_c11003_ } \\
17857759\end{array}$ & 7B & 77.2 & $5.26 \mathrm{E}-04$ & 20.88 & + & \\
\hline
\end{tabular}

